\title{
Physical and Biological Properties of a Chitosan Hydrogel Scaffold Associated to Photobiomodulation Therapy for Dental Pulp Regeneration: An In Vitro and In Vivo Study
}

\author{
Maria Stella Moreira $\mathbb{D},{ }^{1,2}$ Giovanna Sarra $\mathbb{D},{ }^{3}$ Giovanna Lopes Carvalho $\mathbb{D},{ }^{2}$ \\ Flavia Gonçalves $\mathbb{D}^{1},{ }^{1}$ Hector Valentin Caballero-Flores ${ }^{(D)}{ }^{3}$ Ana Clara Fagundes Pedroni, ${ }^{1}$ \\ Cesar Angelo Lascala, ${ }^{4}$ Luiz Henrique Catalani, ${ }^{5}$ and Márcia Martins Marques $\mathbb{D}^{1}$ \\ ${ }^{1}$ Post-Graduation Program in Dentistry, School of Dentistry, Ibirapuera University, São Paulo, Brazil \\ ${ }^{2}$ A.C. Camargo Cancer Center, Stomatology Department, São Paulo, Brazil \\ ${ }^{3}$ Department of Restorative Dentistry, School of Dentistry, Universidade de São Paulo, São Paulo, Brazil \\ ${ }^{4}$ Department of Stomatology, School of Dentistry, Universidade de São Paulo, São Paulo, Brazil \\ ${ }^{5}$ Department of Fundamental Chemistry, Chemical Institute, Universidade de São Paulo, São Paulo, Brazil \\ Correspondence should be addressed to Márcia Martins Marques; marcia.marques@ibirapuera.edu.br
}

Received 13 December 2020; Revised 7 January 2021; Accepted 12 January 2021; Published 27 January 2021

Academic Editor: Iole Vozza

Copyright (c) 2021 Maria Stella Moreira et al. This is an open access article distributed under the Creative Commons Attribution License, which permits unrestricted use, distribution, and reproduction in any medium, provided the original work is properly cited.

\begin{abstract}
Background. The regeneration of dental pulp, especially in cases of pulp death of immature teeth, is the goal of the regenerative endodontic procedures (REPs) that are based on tissue engineering principles, consisting of stem cells, growth factors, and scaffolds. Photobiomodulation therapy (PBMT) showed to improve dental pulp regeneration through cell homing approaches in preclinical studies and has been proposed as the fourth element of tissue engineering. However, when a blood clot was used as a scaffold in one of these previous studies, only $30 \%$ of success was achieved. The authors pointed out the instability of the blood clot as the regeneration shortcoming. Then, to circumvent this problem, a new scaffold was developed to be applied with the blood clot. The hypothesis of the present study was that an experimental injectable chitosan hydrogel would facilitate the threedimensional spatial organization of endogenous stem cells in dental pulp regeneration with no interference on the positive influence of PBMT. Methods. For the in vitro analysis, stem cells from the apical papilla (SCAPs) were characterized by flow cytometry and applied in the chitosan scaffold for evaluating adhesion, migration, and proliferation. For the in vivo analysis, the chitosan scaffold was applied in a rodent orthotopic dental pulp regeneration model under the influence of PBMT (660 nm; power output of $20 \mathrm{~mW}$, beam area of $0.028 \mathrm{~cm}^{2}$, and energy density of $5 \mathrm{~J} / \mathrm{cm}^{2}$ ). Results. The scaffold tested in this study allowed significantly higher viability, proliferation, and migration of SCAPs in vitro when PBMT was applied, especially with the energy density of $5 \mathrm{~J} / \mathrm{cm}^{2}$. These results were in consonance to those of the in vivo data, where pulp-like tissue formation was observed inside the root canal. Conclusion. Chitosan hydrogel when applied with a blood clot and PBMT could in the future improve previous results of dental pulp regeneration through cell homing approaches.
\end{abstract}

\section{Introduction}

Dental pulp is a connective tissue with neuroectodermic origin that is confined inside rigid dentine walls. The blood vessels of dental pulp enter and leave the tooth only through the apical foramen. In case of dental pulp necrosis in response to harmful stimuli, such as caries or trauma, this anatomical situation impairs dental pulp regeneration. The regeneration of dental pulp, especially in cases of pulp death of immature teeth, is the goal of the regenerative endodontic procedures (REPs) that are based on tissue engineering elements, consisting of stem cells, growth factors, and scaffolds [1-3]. Recent advances in dental pulp tissue engineering allow for a gradual translation from bench to clinic. In particular, 
tissue engineering based on cell homing approaches in revitalization procedures offers a biology-based and clinically feasible treatment option for teeth with pulp necrosis.

Photobiomodulation therapy (PBMT) was proposed as another important element for tissue engineering because PBMT has properties able to improve stem cell response [4]. PBMT when applied with adequate parameters improves the in vitro stem cell proliferation, migration, and differentiation [4-9]. Additionally, in preclinical and clinical studies, the PBMT has shown improvement in the regeneration of tissues surrounded by mineralized tissues, where the vascularization can be compromised, such as the jaw bone $[10,11]$ and dental pulp [12-14].

Moreira et al. showed that the pulp revitalization procedures based on cell homing approaches evoked a blood clot into the root canal as a scaffold for dental pulp regeneration. The authors showed success only when applying PBMT. However, the authors pointed out the instability of the blood clot as a regeneration shortcoming. This showed the importance of the scaffold quality to enhance the scaffolds' cellular activities of stem cells for the success of dental pulp regeneration.

Advances in the development of scaffold materials have made biological therapies in regenerative endodontic treatment procedures more effective and feasible. The hydrogels from natural origin have been frequently used as scaffolds because they are composed of molecules of the extracellular matrix (ECM) or of components similar to ECM molecules $[15,16]$. Gelatin, collagen, hyaluronic acid, alginate, and chitosan are some examples of natural scaffolds [16]. However, the most appropriate injectable natural scaffold for dentin pulp regeneration has not been developed $[16,17]$. Among the range of existing scaffolds, chitosan is a widely used biomaterial, which has several biological properties [17-19].

Chitosan is a bioactive natural polysaccharide that has great biocompatibility, biodegradability, and hemostatic potential; it promotes cell adhesion, proliferation, and differentiation; it has a broad antimicrobial effect; it does not cause an immune reaction; it is not carcinogenic; and in addition, having a potential for cell homing has also been associated to this biomaterial [20-27]. Furthermore, chitosan can be used as a thermosensitive hydrogel whose gelation occurs

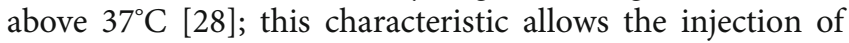
the material in a fluid state inside the pulp chamber and gelation of the biomaterial by the body temperature, increasing the stability of the biomaterial and being a key factor for applications in pulp regeneration. Aimed at presenting an alternative tissue engineering approach for regenerating tissues surrounded by mineralized tissue, such as the dental pulp, the objective of this study was to evaluate the biological responses of stem cells grown inside an experimental injectable hydrogel chitosan scaffold and submitted to PBMT and evaluate the pulp regeneration capacity in an orthotopic model in rats. The hypothesis of this study was that an experimental injectable chitosan hydrogel would facilitate the three-dimensional spatial organization of endogenous stem cells in dental pulp regeneration associated with PBMT on these cells.

\section{Materials and Methods}

The study was approved by the Ethical Committee of the School of Dentistry of the University of São Paulo (\#CAAE 40392214.5.0000.0075).

\subsection{Biomaterial}

2.1.1. Chitosan Synthesis. The high-molecular weight and low-acetylation chitosan powder was dissolved in $0.1 \mathrm{M}$ hydrochloric acid solution (Synth, SP, Brazil). After complete solubilization, the chitosan solution $(11 \mathrm{mg} / \mathrm{l}$ concentration; $\mathrm{pH}$ 7.4) was kept under stirring on an ice bath. Then, a solution of $\beta$-glycerophosphate disodium salt hydrate (crosslinker $)$ in the concentration of $286 \mathrm{mg} / \mathrm{ml}(20 \% \mathrm{w} / \mathrm{v})$ was slowly dripped. After homogenization, this pregel solution was stored at $8^{\circ} \mathrm{C}$. The experiments were conducted keeping the biomaterial constantly refrigerated in ice chips.

2.1.2. Chitosan Viscosity. Chitosan pregel when incubated at $37^{\circ} \mathrm{C}$ for 1 hour becomes a hydrogel. The initial viscosity of this chitosan hydrogel was measured. Then, the chitosan hydrogel was kept at $37^{\circ} \mathrm{C}$ at two different conditions: in the presence of phosphate-buffered saline (PBS chitosan hydrogel (CHP) group) or in the absence of PBS (PBS absent chitosan hydrogel (CHPA) group). In the CHP group, the PBS was added two hours after the incorporation of the crosslinker into the chitosan solution $(2 \mathrm{ml}$ of hydrogel $/ 1 \mathrm{ml}$ of PBS). The viscosity was measured at 24,72 , or 168 hours in a Brookfield viscometer (Model DV-III) with spindle 52 at $40^{\circ} \mathrm{C}$ and $250 \mathrm{rpm}, 5$ minutes after rotation started.

2.1.3. Scanning Electron Microscopy (SEM). Hydrogel ultrastructure was observed in SEM images. Specimens of chitosan hydrogel were frozen at $-20^{\circ} \mathrm{C}$ for $24 \mathrm{~h}$ to further obtain mechanically fractured surfaces. Fractured samples were then placed on metallic stubs, gold-sputtered, and evaluated in scanning electron microscopy.

2.1.4. Stem Cell Culture and Flow Cytometry Analysis. Human SCAPs (stem cells from the apical papilla) isolated from adult teeth were grown in clonogenic medium: $\alpha$ Minimum Essential Medium complemented with 15\% fetal bovine serum (FBS), $100 \mu \mathrm{M} \mathrm{L}$-ascorbic acid-2-phosphate, $100 \mu \mathrm{g} / \mathrm{ml}$ streptomycin, $100 \mathrm{U} / \mathrm{ml}$ penicillin, and $2 \mathrm{mM}$ L-glutamine (all from Gibco/Invitrogen, Grand Island, NY, US). Aliquots of SCAPs $\left(1 \times 10^{6}\right.$ cells $)$ were used for analyzing their immunophenotype profile, as previously described [29].

2.1.5. Three-Dimensional Cell Culture: Cell Adhesion Assay. A volume of $1 \mathrm{ml}$ of chitosan pregel (chitosan solution + crosslinker) was placed at the bottom of a $35 \mathrm{~mm}$ diameter culture plate. The mixture in the plates was homogenized in a shaker and incubated in a humid atmosphere containing 5\% $\mathrm{CO}_{2}$, at $37^{\circ} \mathrm{C}$, for 10 minutes to allow hydrogel formation. Then, SCAPs $\left(1 \times 10^{6}\right.$ cells/plate $)$ were plated on the top of the chitosan hydrogel. These SCAPs were analyzed under SEM 24 hours after seeding, following the same SEM methodology described above. 


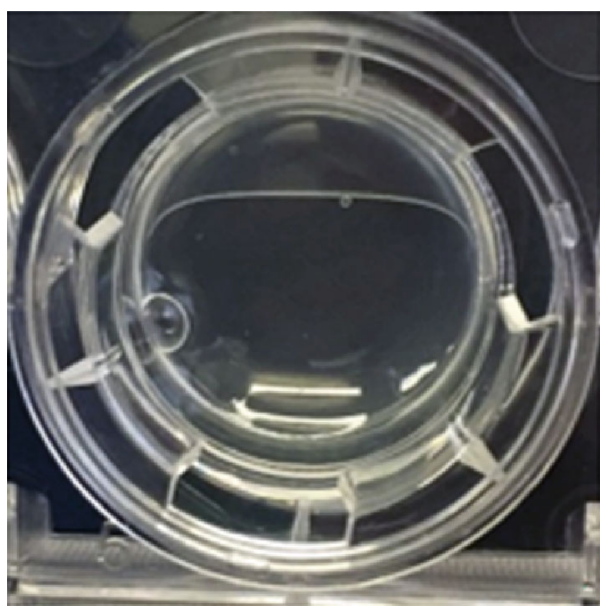

(a)

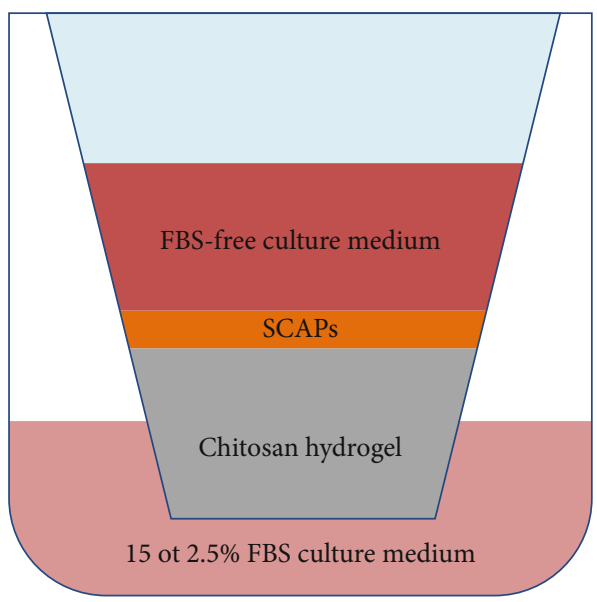

(b)

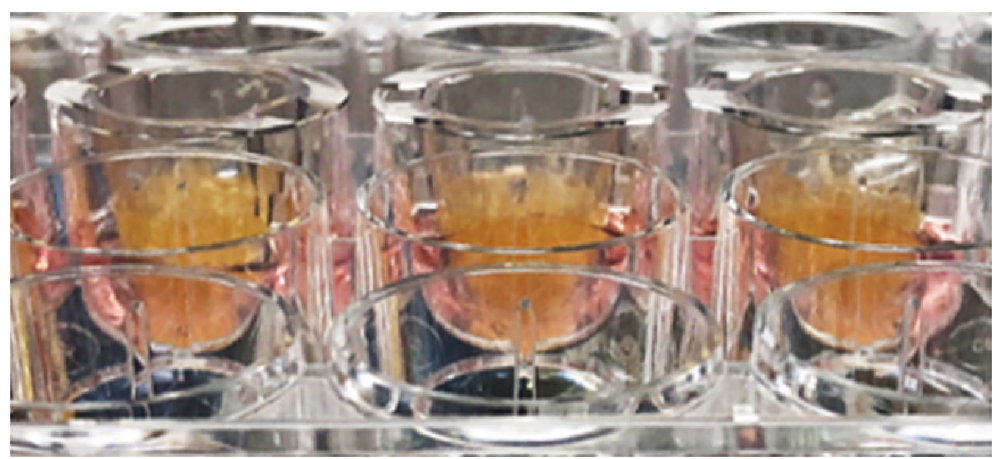

(c)

Figure 1: (a) Aspect of the chitosan hydrogel in the insert. (b) Diagram showing a Transwell insert (upper chamber) placed in the culture well (lower chamber) separated by an $8 \mu \mathrm{m}$ pore size filter. The lower chamber contains culture medium supplemented with 15 or $2.5 \%$ of FBS, whereas the upper chamber presents serum-free culture medium. (c) System for Transwell migration assay.

2.1.6. Three-Dimensional Cell Culture: Proliferation Assay. For cell proliferation assay, $100 \mu \mathrm{l}$ of chitosan solution was placed at the bottom of 96-well plates. SCAP pellets were resuspended in the crosslinker $\left(1 \times 10^{5}\right.$ cells per well $)$ and then incorporated into the chitosan solution inside the wells. The mixture in the plates was homogenized in a shaker. This pregel (chitosan solution+crosslinker) containing the cells was then incubated in a humid atmosphere with $5 \% \mathrm{CO}_{2}$ at $37^{\circ} \mathrm{C}$ for 10 minutes to allow hydrogel formation. The plates were assigned to one of the following three experimental groups: Group 1 (positive control): no further treatment (nonirradiated); Group $2\left(\mathrm{PBMT} 3 \mathrm{~J} / \mathrm{cm}^{2}\right)$ : cells treated with PBMT using $3 \mathrm{~J} / \mathrm{cm}^{2}$; and Group $3\left(\mathrm{PBMT} 5 \mathrm{~J} / \mathrm{cm}^{2}\right)$ : cells treated with PBMT using $5 \mathrm{~J} / \mathrm{cm}^{2}$.

The cell viability of SCAPs grown inside the chitosan hydrogel under PBMT (3 or $5 \mathrm{~J} / \mathrm{cm}^{2}$ ) or not (control) was analyzed using the MTT reduction assay, as described elsewhere [30] at 72 and 120 hours after seeding. The absorbance was measured in a microplate reader (Biotek II, Biochrom Ltd., Eugendorf, Austria) with a 562 nm filter.

2.1.7. Photobiomodulation Therapy. Photobiomodulation therapy was applied using a continuous-wave indium-gallium-aluminum-phosphide (InGaAlP) diode laser (660 nm;
DMC, São Carlos, SP, Brazil) with a spot size of $0.028 \mathrm{~cm}^{2}$. The following parameters were used in contact and punctual irradiation mode: $20 \mathrm{~mW}, 0.71 \mathrm{~W} / \mathrm{cm}^{2}, 3 \mathrm{~J} / \mathrm{cm}^{2}$ (4s) or $5 \mathrm{~J} / \mathrm{cm}^{2}(7 \mathrm{~s})$, and $0.08 \mathrm{~J}$ or $0.14 \mathrm{~J}$, respectively. Irradiations were applied twice (6 and $12 \mathrm{~h}$ after seeding) underneath each well (for 96-well plates in the center and for 24-well plates in five equidistant points). The output power was checked with a power meter (LaserCheck, Coherent Inc., Santa Clara, CA, US) before and after the irradiations. The control groups were under the same conditions as the irradiated groups, but the laser equipment was kept off. The PBMT parameters were defined as previously described in the literature $[5,7,14]$.

2.1.8. Three-Dimensional Cell Culture: Migration Assay. Transwell migration assay was carried out with a Transwell system (Corning, New York, NY, US) composed of a Transwell insert (upper chamber) placed in the culture wells (lower chamber) of 24 -well plates separated by an $8 \mu \mathrm{m}$ pore size filter. A volume of $500 \mu \mathrm{l}$ of chitosan pregel was placed at the upper chamber on the top of the filter. The plates were maintained on shaker agitation and incubation as previously described, allowing hydrogel formation (Figure 1(a)). Figures 1(b) and 1(c) illustrate the preparation of the 
migration assay and the system. Culture medium supplemented with 15\% FBS (positive control) or $2.5 \%$ FBS (negative control and both PBMT groups) was added at the lower chamber. The cells were seeded at the top of the chitosan hydrogel $\left(1 \times 10^{5}\right.$ cells per insert), and the upper chamber was filled with $200 \mu \mathrm{l}$ of serum-free culture medium. Then, these Transwell plates were assigned to one of the four experimental groups: Group 1 (positive control): lower chamber containing culture medium complemented with $15 \%$ FBS; Group 2 (negative control): lower chamber containing culture medium complemented with $2.5 \%$ FBS; Group 3 (PBMT $3 \mathrm{~J} / \mathrm{cm}^{2}$ ): lower chamber containing culture medium complemented with $2.5 \%$ FBS and treated with PBMT using $3 \mathrm{~J} / \mathrm{cm}^{2}$; and Group $4\left(\right.$ PBMT $\left.5 \mathrm{~J} / \mathrm{cm}^{2}\right)$ : lower chamber containing culture medium complemented with 2.5\% FBS and treated with PBMT using $5 \mathrm{~J} / \mathrm{cm}^{2}$. The cell migration was analyzed in all experimental groups at 18 and 48 hours after the SCAP seeding as previously described [31]. Then, the absorbance was measured with a microplate reader (Biotek II, Biochrom Ltd., Eugendorf, Austria) with a $560 \mathrm{~nm}$ filter.

2.1.9. In Vivo Orthotopic Dental Pulp Model. Thirty-four adult male Wistar rats (Rattus norvegicus albinus) weighing an average of 350 to $375 \mathrm{~g}$ and approximately 13 weeks old were used in this study. The rats were anesthetized and fixed on a frame/operative board. Dental pulp from the upper right first molar was surgically exposed, and the pulp of the mesial root canal was removed through instrumentation up to ISO 25 . Then, the animals were randomly divided into 4 groups:

(i) Chitosan scaffold

(ii) Chitosan scaffold+PBMT

(iii) Blood clot+chitosan scaffold

(iv) Blood clot+chitosan scaffold+PBMT

After canal root preparation, a blood clot was evoked as described previously for the hybrid scaffold groups [14], and the root canal was filled with $5 \mu$ l of chitosan. The PBMT was carried out in contact with the crown of the tooth, over the mix of blood and chitosan, in a single point, as previously described [14]. A red laser was chosen because of its interaction with the blood clotting hemoglobin. The animals in the groups without PBMT were kept in the same condition as animals of the PBMT groups, but with the laser equipment turned off. Rats were euthanized 28 days posttreatment, and their maxillae were processed for further histological analysis. The upper left first molars were used as controls for future comparisons of the tissue formation. In vivo procedures and treatments were performed by a single operator (endodontist), previously trained and calibrated.

2.1.10. Histology. The samples were fixed into $10 \%$ buffered formalin solution, decalcified in 4\% EDTA solution ( $\mathrm{pH} 7.4$ ), dehydrated, and embedded in paraffin. Tissue specimens were sectioned at $5 \mu \mathrm{m}$ and stained with hematoxylineosin (H\&E). The neoformed tissues into the root canal were analyzed by endodontic and pathology experts that were previously calibrated.

2.1.11. Immunohistochemistry. Immunohistochemistry was performed using an antibody against HSP-25 to identify odontoblast-like cells following the methodology described previously [14].

2.1.12. Statistical Analysis. All experiments were repeated at least three times. Two-way analysis of variance (ANOVA), complemented by Tukey's test, was applied. The level of significance was set at $p \leq 0.05$. Quantitative data were expressed as the mean \pm standard deviation (SD).

\section{Results}

3.1. Chitosan Viscosity. The viscosity of the chitosan hydrogel increased as a function of time (Figure 2(a)). It was possible to observe an increase of more than 10 -fold in the viscosity of the hydrogel kept incubated at $37^{\circ} \mathrm{C}$ for 168 hours (CHPA). The immersion of the hydrogel into PBS (CHP) led to a gel swelling and degradation process, with a reduction of $62 \%$ in the $\mathrm{CHP}$ viscosity in 24 hours and $30 \%$ after 168 hours when comparing to the CHPA.

3.2. Hydrogel Ultrastructure and Cell Adhesion. Illustrative scanning electron micrographs of a cross-sectional aspect of the chitosan hydrogel scaffold are presented in Figure 2(b). This ultrastructure resembles a honeycomb with pores of variable diameters interconnected to each other (Figure 2(b)). When the cells were plated inside the chitosan hydrogel, they form clusters of round cells in contact with the walls of the pores (Figure 2(c)).

3.3. Stem Cell Characterization. SCAPs expressed levels of specific MSC surface markers, such as CD146, CD44, and CD105, and lacked the expression of the nonspecific markers of MSCs: CD45, CD34, and CD14 (Figure 3).

3.4. Cell Proliferation. Figure 4(a) illustrates the results obtained from the MTT assay at 72 and 120 hours after cell seeding. At 72 hours, both PBMT groups showed increased cell proliferation compared to the control group. At 120 hours, only the PBMT $5 \mathrm{~J} / \mathrm{cm}^{2}$ group presented a higher number of cells than the control group. At this experimental time, the PBMT $3 \mathrm{~J} / \mathrm{cm}^{2}$ group presented viability similar to the control and PBMT $5 \mathrm{~J} / \mathrm{cm}^{2}$ groups.

3.5. Migration. Figure 4(b) presents the number of migrating cells at 18 and 48 hours after seeding. At the experimental time of 18 hours, both PBMT groups ( 3 and $5 \mathrm{~J} / \mathrm{cm}^{2}$ ) presented increased cell migration through the chitosan scaffold when compared to the control groups (15 and $2.5 \%$ FBS). At 48 hours, the highest migration occurred in the PBMT $5 \mathrm{~J} / \mathrm{cm}^{2}$ group $(p<0.0001)$, and the all other groups presented similar migration.

3.6. In Vivo Study. Two animals died at the surgery procedure. Thus, 32 teeth were retrieved for histological analysis. Representative histological sections of specimens from the in vivo study are presented in Figure 5 . When the root canal 


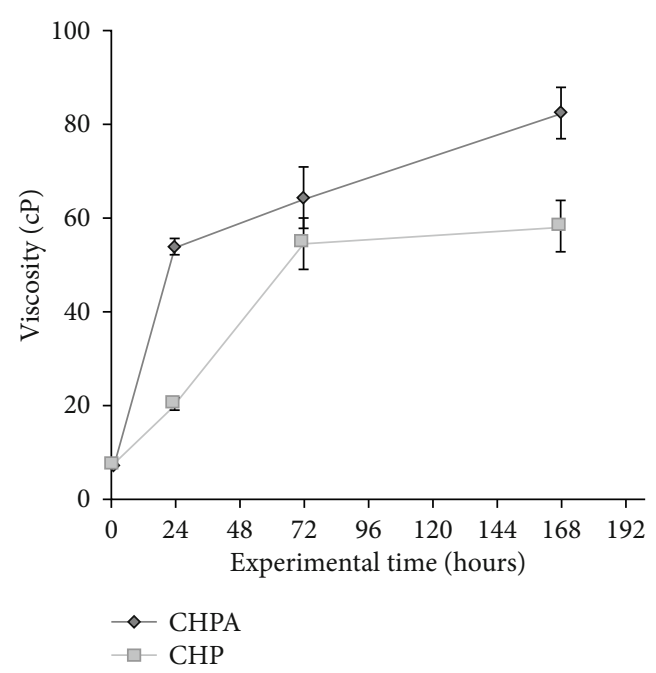

(a)

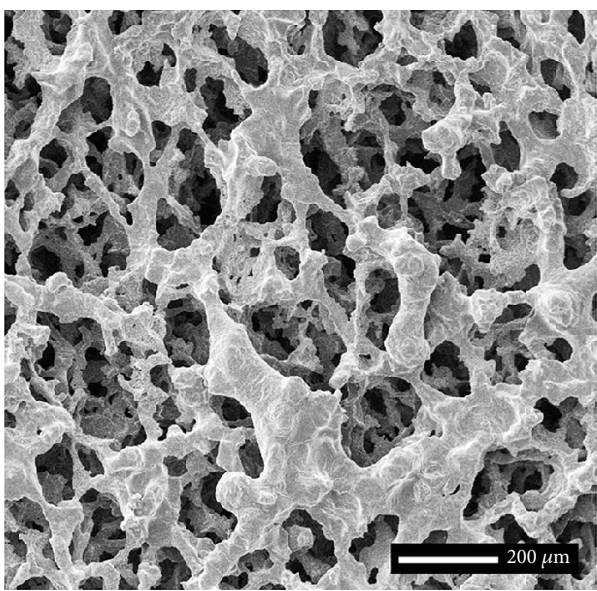

(b)

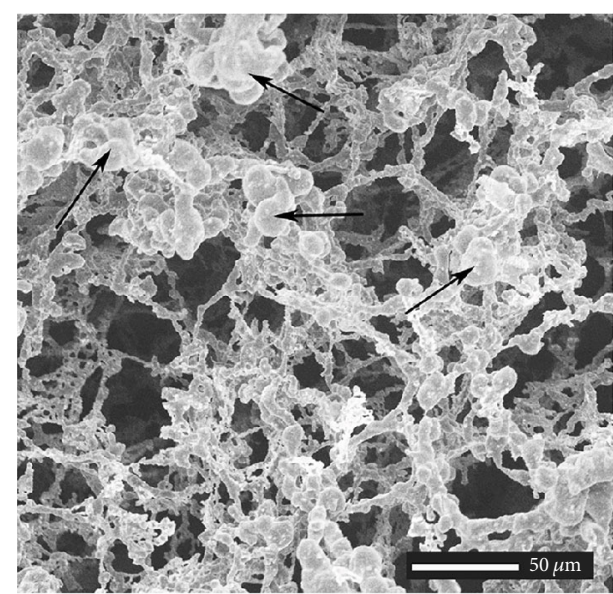

(c)

FIgURE 2: (a) Graphical representation of the viscosity of the PBS absent chitosan hydrogel (CHPA) and the chitosan hydrogel immersed into PBS (CHP) at $37^{\circ} \mathrm{C}$ as a function of time. (b) Illustrative scanning electron micrographs of chitosan hydrogel and (c) chitosan hydrogel seeded with SCAPs. Observe the rounded shape of the cells forming clusters of diverse sizes on top of the hydrogel beams (arrows).

was filled with the chitosan scaffold alone and photoactivated, it was possible to observe poor-developed tissue formation, and when it was filled with the hybrid scaffold (blood clot and chitosan), avascular tissue was observed. Well-developed pulp-like tissue with the presence of predentin along the root canal walls was observed at 4 weeks in the hybrid scaffold (blood clot+chitosan hydrogel) and PBMT group. This tissue was rich in newly formed vessels with rounded endothelial cell walls, and neither inflammation nor internal/external resorption was detected. In one tooth of this group, a layer of cells was observed in intimate contact with the dentin wall exhibiting cytoplasmic extensions penetrating the dentin tubules (Figures 5(a) and 5(b)). The healthy dental pulp tissue presented predentin and very developed and differentiated vessels with thin endothelial cell walls (Figures 5(c) and 5(d)). The newly formed tissue in the blood clot+chitosan+PBMT group was characterized by immunohistochemistry in order to identify odontoblast-like cells. Cells that were in intimate contact with the predentin lining were positive for the HSP-25 marker (Figures 5(e) and 5(f)).

\section{Discussion}

The typical treatment of pulp-compromised teeth is the root canal treatment. However, regenerative endodontic procedures, which are aimed at regenerating the dental pulp tissue, are potential alternative approaches. Two possible strategies have been explored: cell-based or cell-free (cell homing). The last one employs the host's endogenous stem cells from the apical papilla and is considered a less complex procedure and more clinically translatable. Nevertheless, the studies presented to date still point to the need for a further understanding and improvement of the cell homing strategies in order to achieve a more structured tissue morphologically and functionally similar to the dental pulp [32].

Pulp regeneration based on regenerative endodontic procedures under photobiomodulation therapy (PBMT) has shown favorable results in preclinical studies $[12,14]$ and might be a feasible alternative to cell-based therapies. However, the instability of the blood clot was pointed to as one of the regeneration shortcomings when a blood clot was used 

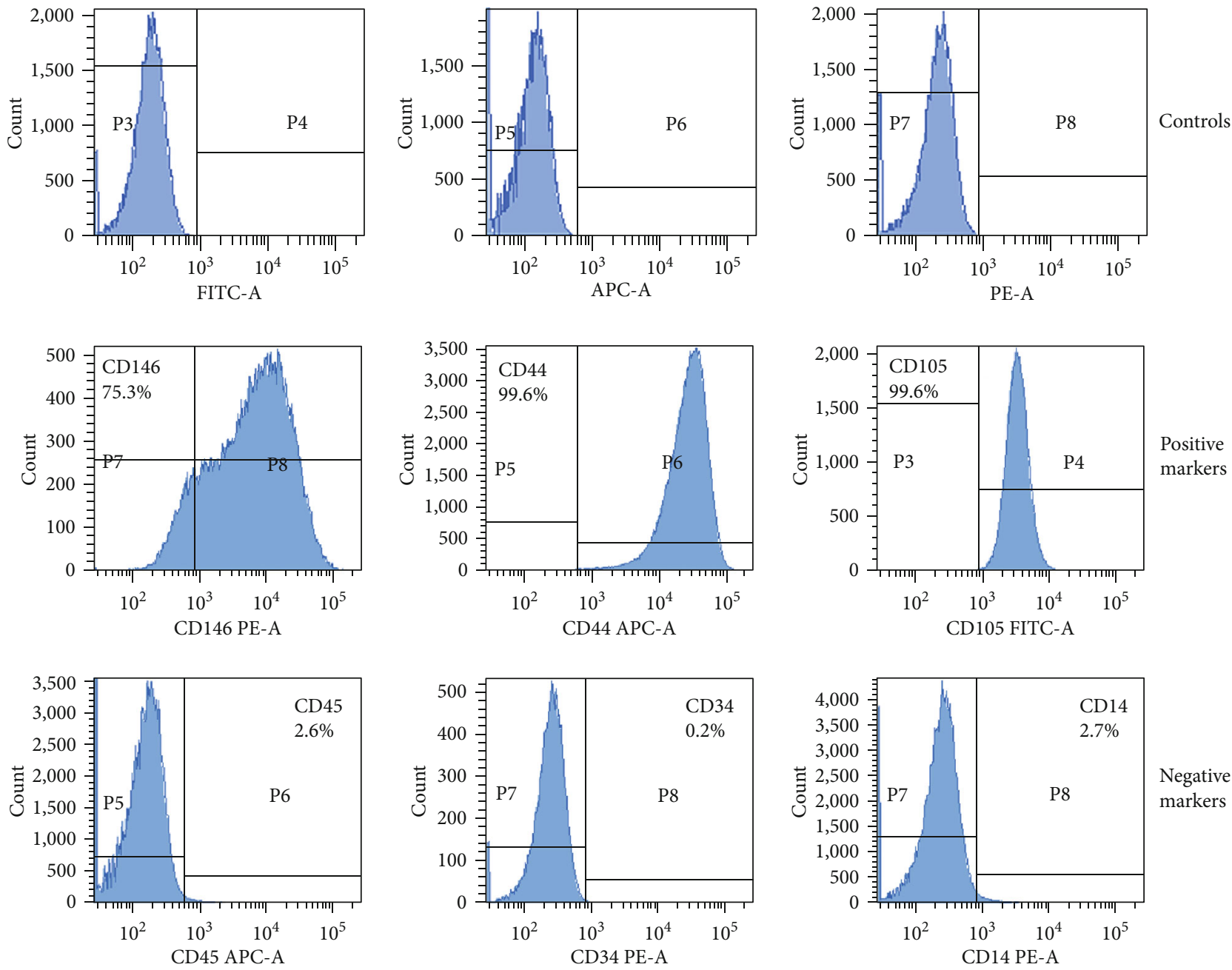

Figure 3: Immunoprofile of the surface molecules of the SCAPs. Positive for CD146, CD44, and CD105 and negative for CD45, CD34, and CD14, classical for mesenchymal stem cells.

as a scaffold for cell homing dental pulp regeneration. To circumvent this and owing to the anatomical complexity of the root canal system, the focus on injectable hydrogel scaffolds for cell homing seems to be promising since its physical properties should favor the filling of the channels, as well as allow the migration of stem cells $[33,34]$.

Thus, the purpose of the present study was to evaluate the biological responses of stem cells grown inside an experimental thermosensitive and injectable hydrogel chitosan scaffold and submitted to PBMT, seeking to take advantage of the association of both approaches. The hypothesis was that the injectable chitosan hydrogel would facilitate the threedimensional spatial organization of endogenous stem cells with the positive influence of PBMT on stem cell viability, migration, and differentiation. The biological and physical properties of this scaffold were tested in vitro with and without PBMT.

Chitosan in contact with dental stem cells in vitro promotes viability, adhesion, proliferation, and neural or odontogenic differentiation [35-39]. The chitosan hydrogel presented low viscosity due to its thermosensitive property, so it could be easily injected into the root canal. In contact with the body temperature, gelation occurs, and the viscosity is progressively increased, so it could allow the migration of the stem cells, and after that, it stabilized in a moderate viscosity with good integrity surface for regeneration. Moreover, the chitosan hydrogel presented interconnected pores, which facilitated the nutrition of stem cells inside the pores. These physical characteristics probably helped the stability of a hybrid scaffold (e.g., chitosan+blood clot) for cell homing dental pulp regeneration. In the SEM images, it was possible to notice that the stem cells used in this study (stem cells derived from the dental papilla (SCAPs)) were arranged in clusters inside the scaffold pores. Although they maintained their round shape and did not spread, they were in contact with the walls of the pores.

Photobiomodulation therapy (PBMT) was proposed by Marques et al. as "the fourth element of tissue engineering along with stem cells, scaffolds, and growth factors" [4]. This is because, due to its properties, PBMT can overcome some of the drawbacks of tissue engineering. PBMT when applied with adequate parameters modulates inflammation and improves cell migration, proliferation, and cell differentiation $[5-8,40-42]$, enhancing tissue formation. In the review 


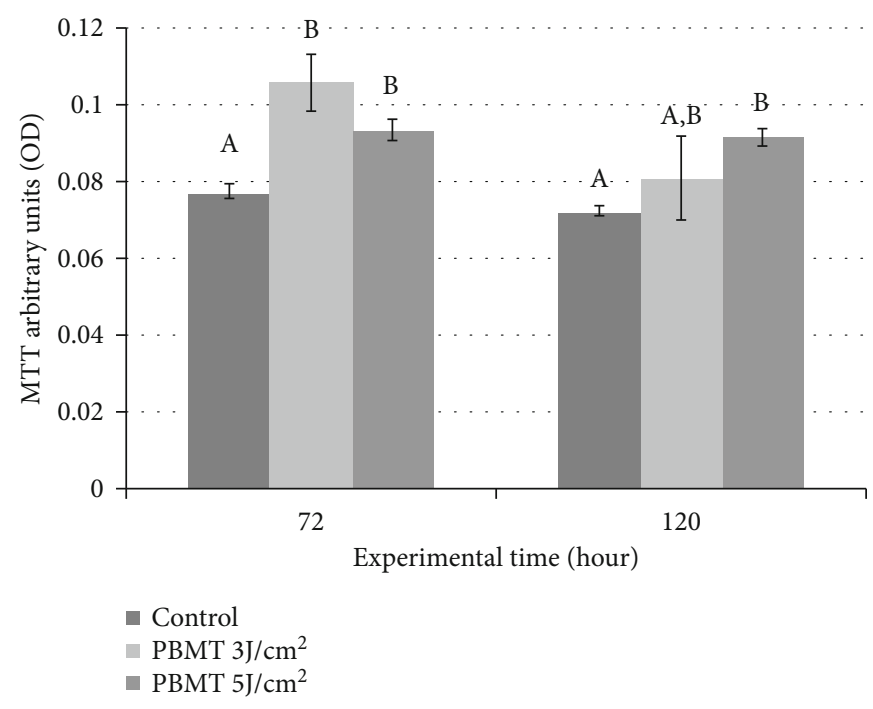

(a)

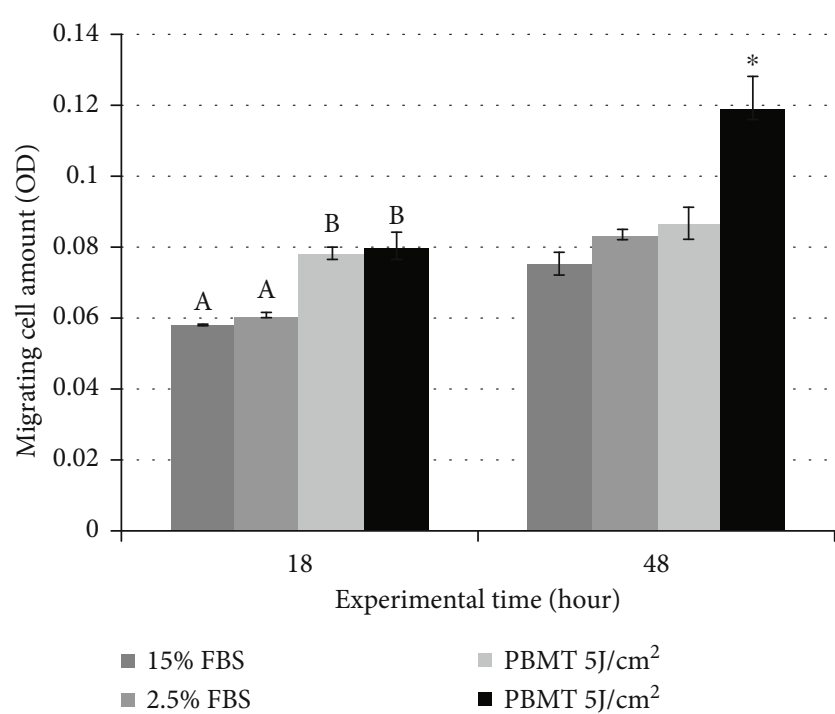

(b)

FIGURE 4: (a) Graphical representation of the number of vital cells of all experimental groups in the function of time. Different letters show statistically significant differences between groups at $72 \mathrm{~h}$, whereas different capital letters show statistically significant differences between groups at $120 \mathrm{~h}(p<0.05)$. (b) Graphical representation of the number of migrating cells of all experimental groups at 18 and 48 hours after cell seeding. Different letters show statistically significant differences between groups at the experimental time of 18 hours. * Differences between the PBMT $5 \mathrm{~J} / \mathrm{cm}^{2}$ group and all other groups at 48 hours $(p<0.0001)$.

conducted by Staffoli et al., the results showed that DPSCs (dental pulp stem cells) responded positively to laser phototherapy by improving cell growth and also suggested that PBMT may be an important tool for tissue engineering associated to stem cells [9]. In the present in vitro study, the influence of PBMT was observed; the SCAPs grown inside the chitosan scaffold under PBMT presented enhanced proliferation and migration, especially when the energy density of $5 \mathrm{~J} / \mathrm{cm}^{2}$ was applied. These findings point out a positive response of SCAPs inside chitosan to PBMT. In fact, the possible cell sources for pulp regeneration through cell homing include dental pulp stem cells (DPSCs), stem cells from the apical papilla (SCAPs), and bone marrow stem cells (BMSCs) [43-45].

The PBMT applied with the energy density of $5 \mathrm{~J} / \mathrm{cm}^{2}$ presented the most striking results for both tests, proliferation and migration. This parameter has been consistently positive in former in vitro studies [4, 7, 46, 47]. Marques et al. reviewed the effects of PBMT on stem cells from dental stem cells and found that the $5 \mathrm{~J} / \mathrm{cm}^{2}$ energy density at $660 \mathrm{~nm}$ wavelength induced high rates of cell viability and proliferation. Moura-Netto et al. also reported an enhanced proliferation of stem cells from exfoliated deciduous teeth (SHEDs) under these same PBMT parameters during situations of nutritional deficit [46]. Moreover, Ferreira et al. investigated dental pulp stem cells (DPSCs) encapsulated in an injectable recombinant human Bone Morphogenetic Protein 4- (rhBMP4-) loaded hydrogel and showed that the $5 \mathrm{~J} / \mathrm{cm}^{2}$ energy density improved cell survival in vitro and also accelerated hard tissue formation in vivo. In a shortterm analysis, PBMT at $5 \mathrm{~J} / \mathrm{cm}^{2}$ increased the number of SHEDs with no interference on their undifferentiated state [47]. In most of these studies, the PBMT was applied to cells in a stress condition. Culture medium with reduced FBS concentration causes a nutrition deficiency status with decreased cellular growth that is an appropriate condition to observe the effects of PBMT $[5,48,49]$. In the present study, this nutritional deficit approach was not necessary once the contact with the chitosan hydrogel already would represent a condition of stress. And in fact, the effects of PBMT were noticeable in the proliferation and migration analysis, mostly due to this stress condition.

Based on the in vitro results, we chose the energy density of $5 \mathrm{~J} / \mathrm{cm}^{2}$ as the parameter to be used in the in vivo study. The root canals were filled with blood clot+chitosan hydrogel (hybrid scaffold), and the PBMT was carried out in contact with the crown of the tooth after the procedure. The histological analysis showed that the mesial root canal was filled with an immature connective tissue, with newly formed vessels, with morphology similar to that of healthy pulp. The immunohistochemistry identified odontoblast-like cells in intimate contact with the predentin lining. Probably, the root canal system filled with the chitosan hydrogel scaffold provided stability to the blood clot allowing the migration and adhesion of the stem cells attracted by the provoked bleeding from the root end. However, this initial colonization does not guarantee the survival of these cells over time. PBMT is a great factor with the potential to maintain cell viability, improving the proliferation and differentiation process. In addition, after stabilization, the cells start to secrete their own extracellular matrix (ECM) that could contain growth factors, which are the third element of tissue engineering and thus important for dental pulp regeneration. In this context, the PBMT also would have importance. In fact, Garrido et al. demonstrated that ECM secreted by human DPSC (dental pulp stem cell) sheets presented a higher amount of 


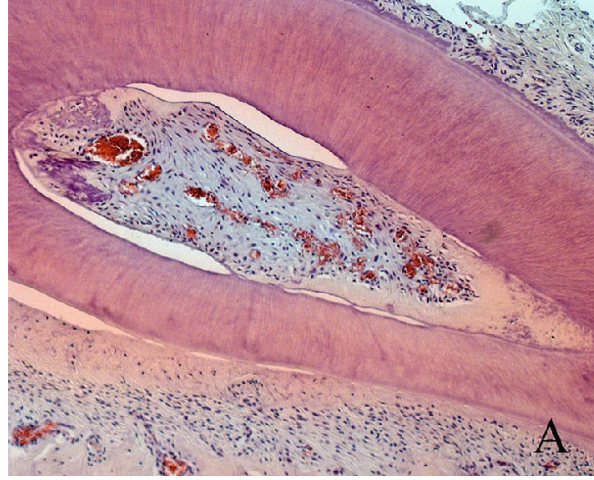

(a)

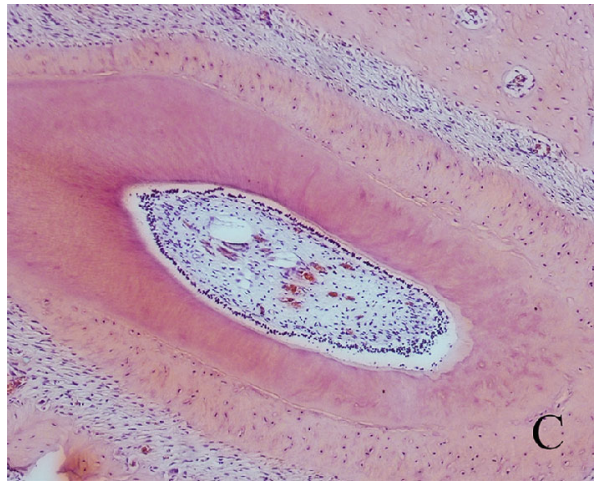

(c)

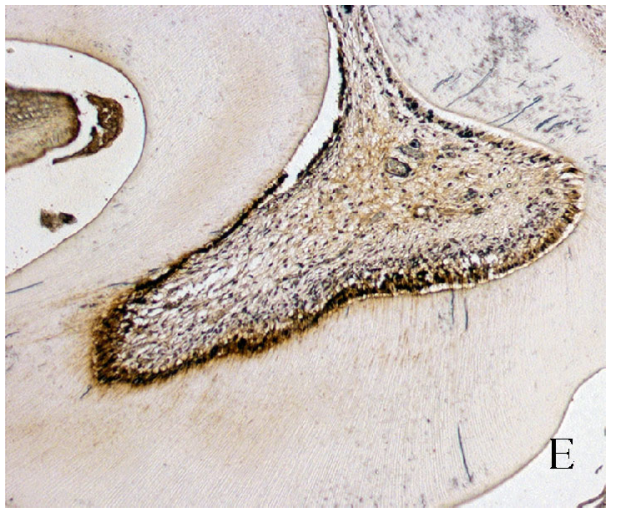

(e)

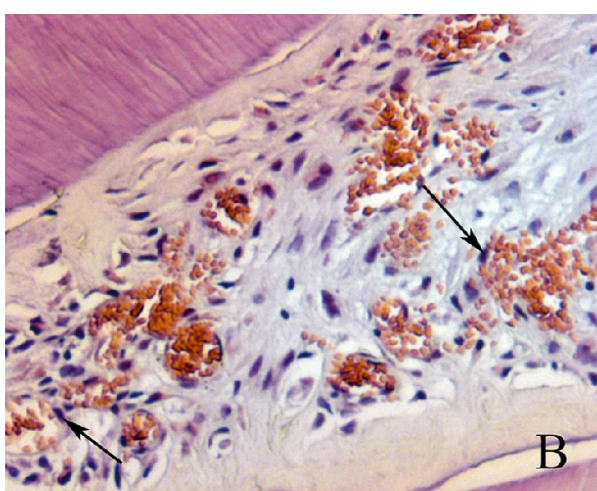

(b)

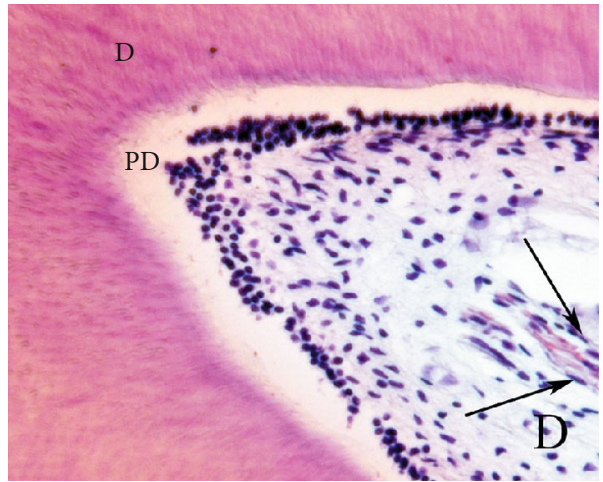

(d)

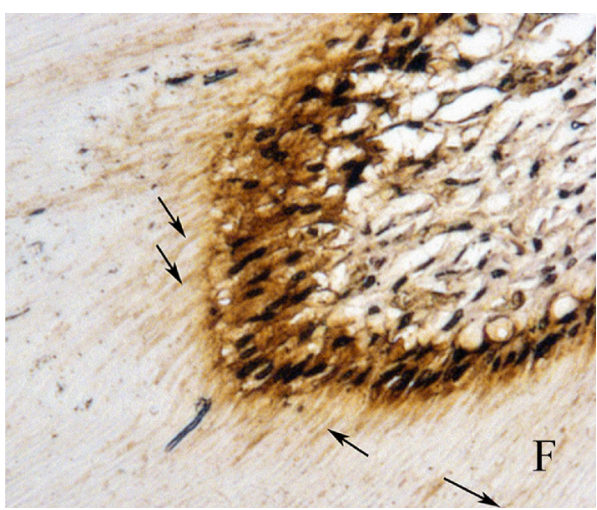

(f)

FIGURE 5: Photomicrographs illustrating the results of the blood clot+chitosan+PBMT group. Observe the newly formed connective tissue inside the root canal $(\mathrm{a}, \mathrm{b})$, with young blood vessels. This newly formed tissue is similar to healthy dental pulp (c, d). The odontoblastlike cells stained with HSP-25 (e, f) are in intimate contact with the predentin (original magnifications of (e) 10x and (f) 40x).

fibronectin when submitted to PBMT [41]. Also, the incorporation of fibronectin in the chitosan scaffold has been investigated and has been shown to influence the cell environment with increased adhesion and proliferation [50]. Then, in the future, the association of the chitosan scaffold with growth factors also can be tested.

In our study, PBMT was performed only after blood clot formation. Zaccara et al. tested the influence of photobiomodulation therapy on root development in rat teeth with pulp necrosis and an open apex, using cell homing and stem cell transplantation (cell-free and cell-based therapies), and the PBMT was performed on $24 \mathrm{~h}$ intervals for 30 days [44, 47, 50, 51]. The results showed that PBMT improved tissue response to apexification and favored the increase in root length and width (apexogenesis). They concluded that daily irradiations are important to maintain the biostimulating effect. Therefore, continuing irradiation in the days after the regenerative endodontic procedure is something that needs to be further investigated in our proposed model and can improve the results found so far.

\section{Conclusions}

The findings of the present study are promising and showed that chitosan hydrogel when applied with a blood clot as a hybrid scaffold and PBMT could in the future improve 
previous results of dental pulp regeneration through cell homing approaches. However, further studies need to be performed, especially those of in vivo cell homing-based dental pulp regeneration with long-term follow-ups.

\section{Data Availability}

All data included in this study are available upon request by contact with the corresponding author.

\section{Conflicts of Interest}

The authors declare that there is no conflict of interest regarding the publication of this paper.

\section{Acknowledgments}

This work was supported by CNPq (\#235015/2014-8) and by FAPESP (2018/14694-8 and 2018/01501-7). MMM is supported by CNPq (\#306423/2018-9).

\section{References}

[1] K. Iohara, S. Utsunomiya, S. Kohara, and M. Nakashima, "Allogeneic transplantation of mobilized dental pulp stem cells with the mismatched dog leukocyte antigen type is safe and efficacious for total pulp regeneration," Stem Cell Research \& Therapy, vol. 9, 2018.

[2] M. Nakashima, K. Iohara, M. C. Bottino, A. F. Fouad, J. E. Nor, and G. T. J. Huang, "Animal models for stem cell-based pulp regeneration: foundation for human clinical applications," Tissue Engineering Part B: Reviews, vol. 25, no. 2, pp. 100-113, 2019.

[3] K. Xuan, B. Li, H. Guo et al., "Deciduous autologous tooth stem cells regenerate dental pulp after implantation into injured teeth," Science Translational Medicine, vol. 10, no. $455,2018$.

[4] M. M. Marques, I. M. A. Diniz, S. P. H. M. de Cara et al., "Photobiomodulation of dental derived mesenchymal stem cells: a systematic review," Photomedicine and Laser Surgery, vol. 34, no. 11, pp. 500-508, 2016.

[5] F. d. P. Eduardo, D. F. Bueno, P. M. de Freitas et al., "Stem cell proliferation under low intensity laser irradiation: a preliminary study," Lasers in Surgery and Medicine, vol. 40, no. 6, pp. 433-438, 2008.

[6] C. Xinaris, M. Morigi, V. Benedetti et al., "A novel strategy to enhance mesenchymal stem cell migration capacity and promote tissue repair in an injury specific fashion," Cell Transplantation, vol. 22, no. 3, pp. 423-436, 2013.

[7] I. M. A. Diniz, A. C. O. Carreira, C. R. Sipert et al., "Photobiomodulation of mesenchymal stem cells encapsulated in an injectable rhBMP4-loaded hydrogel directs hard tissue bioengineering," Journal of Cellular Physiology, vol. 233, no. 6, pp. 4907-4918, 2018.

[8] A. de Farias Gabriel, V. P. Wagner, C. Correa et al., "Photobiomodulation therapy modulates epigenetic events and NF- $\kappa \mathrm{B}$ expression in oral epithelial wound healing," Lasers in Medical Science, vol. 34, no. 7, pp. 1465-1472, 2019.

[9] S. Staffoli, U. Romeo, R. N. S. Amorim et al., "The effects of low level laser irradiation on proliferation of human dental pulp: a narrative review," La Clinica Terapeutica, vol. 168, no. 5, pp. e320-e326, 2017.

[10] M. M. A. Romão, M. M. Marques, A. R. G. Cortes, A. C. R. T. Horliana, M. S. Moreira, and C. A. Lascala, "Micro-computed tomography and histomorphometric analysis of human alveolar bone repair induced by laser phototherapy: a pilot study," International Journal of Oral and Maxillofacial Surgery, vol. 44, no. 12, pp. 1521-1528, 2015.

[11] K. A. V. Rosero, R. M. F. Sampaio, M. C. Z. Deboni et al., "Photobiomodulation as an adjunctive therapy for alveolar socket preservation: a preliminary study in humans," Lasers in Medical Science, vol. 35, no. 8, pp. 1711-1720, 2020.

[12] P. R. Arany, A. Cho, T. D. Hunt et al., "Photoactivation of endogenous latent transforming growth factor- $\beta 1$ directs dental stem cell differentiation for regeneration," Science Translational Medicine, vol. 6, no. 238, p. 238ra69, 2014.

[13] J.-W. Yang, Y.-F. Zhang, C.-Y. Wan et al., "Autophagy in SDF$1 \alpha$-mediated DPSC migration and pulp regeneration," Biomaterials, vol. 44, pp. 11-23, 2015.

[14] M. S. Moreira, I. M. Diniz, M. F. S. D. Rodrigues et al., “_In vivo_ experimental model of orthotopic dental pulp regeneration under the influence of photobiomodulation therapy," Journal of Photochemistry and Photobiology. B, vol. 166, pp. 180-186, 2017.

[15] K. M. Galler, G. Krastl, S. Simon et al., "European Society of Endodontology position statement: revitalization procedures," International Endodontic Journal, vol. 49, no. 8, pp. 717-723, 2016.

[16] K. A. Fukushima, M. M. Marques, T. K. Tedesco et al., "Screening of hydrogel-based scaffolds for dental pulp regeneration-a systematic review," Archives of Oral Biology, vol. 98, 2019.

[17] N. Zein, E. Harmouch, J.-C. Lutz et al., "Polymer-based instructive scaffolds for endodontic regeneration," Materials, vol. 12, no. 15, 2019.

[18] A. Aguilar, N. Zein, E. Harmouch et al., "Application of chitosan in bone and dental engineering," Molecules, vol. 24, no. 16, 2019.

[19] X. Hu, X. Zhou, Y. Li et al., "Application of stem cells and chitosan in the repair of spinal cord injury," International Journal of Developmental Neuroscience, vol. 76, no. 1, pp. 80-85, 2019.

[20] A. Bernkop-Schnürch, "Chitosan and its derivatives: potential excipients for peroral peptide delivery systems," International Journal of Pharmaceutics, vol. 194, no. 1, pp. 1-13, 2000.

[21] Z. Guan, S. Shi, B. Samruajbenjakun, and S. Kamolmatyakul, "Fabrication, characterization and cell cultures on a novel chitosan scaffold," Bio-medical Materials and Engineering, vol. 25, Supplement 1, pp. 121-135, 2015.

[22] I.-Y. Kim, S.-J. Seo, H.-S. Moon et al., "Chitosan and its derivatives for tissue engineering applications," Biotechnology Advances, vol. 26, no. 1, pp. 1-21, 2008.

[23] S. Ravindran and A. George, "Biomimetic extracellular matrix mediated somatic stem cell differentiation: applications in dental pulp tissue regeneration," Frontiers in Physiology, vol. 6, p. 118, 2015.

[24] M. P. Ribeiro, A. Espiga, D. Silva et al., "Development of a new chitosan hydrogel for wound dressing," Wound Repair and Regeneration, vol. 17, no. 6, pp. 817-824, 2009.

[25] A. Shrestha, S. Friedman, C. D. Torneck, and A. Kishen, "Bioactivity of photoactivated functionalized nanoparticles assessed in lipopolysaccharide-contaminated root canals 
_in vivo_, Journal of Endodontia, vol. 44, no. 1, pp. 104-110, 2018.

[26] H. K. No, N. Y. Park, S. H. Lee, and S. P. Meyers, “Antibacterial activity of chitosans and chitosan oligomers with different molecular weights," International Journal of Food Microbiology, vol. 74, no. 1-2, pp. 65-72, 2002.

[27] Z. Liu, H. Wang, Y. Wang et al., "The influence of chitosan hydrogel on stem cell engraftment, survival and homing in the ischemic myocardial microenvironment," Biomaterials, vol. 33, no. 11, pp. 3093-3106, 2012.

[28] A. Chenite, C. Chaput, D. Wang et al., "Novel injectable neutral solutions of chitosan form biodegradable gels in situ," Biomaterials, vol. 21, no. 21, pp. 2155-2161, 2000.

[29] A. C. F. Pedroni, G. Sarra, N. K. de Oliveira, M. S. Moreira, M. C. Z. Deboni, and M. M. Marques, "Cell sheets of human dental pulp stem cells for future application in bone replacement," Clinical Oral Investigations, vol. 23, no. 6, pp. 27132721, 2019.

[30] M. S. Moreira, E. Katayama, A. C. Bombana, and M. M. Marques, "Cytotoxicity analysis of alendronate on cultured endothelial cells and subcutaneous tissue. A pilot study," Dental Traumatology, vol. 21, no. 6, pp. 329-335, 2005.

[31] C. M. França, R. G. Jaeger, V. M. Freitas, N. S. Araújo, and M. M. Jaeger, "Effect of N-CAM on in vitro invasion of human adenoid cystic carcinoma cells," Oral Oncology, vol. 37, no. 8, pp. 638-642, 2001.

[32] S. Eramo, A. Natali, R. Pinna, and E. Milia, "Dental pulp regenerationviacell homing," International Endodontic Journal, vol. 51, no. 4, pp. 405-419, 2018.

[33] T. Fehrenbrach, "M; Popowics," in Illustrated Dental Embryology, Elsevier Inc., Missouri, 2015.

[34] B. Chang, N. Ahuja, C. Ma, and X. Liu, "Injectable scaffolds: preparation and application in dental and craniofacial regeneration," Materials Science and Engineering: R: Reports, vol. 111, pp. 1-26, 2017.

[35] Q. Hu, "Preparation and characterization of biodegradable chitosan/hydroxyapatite nanocomposite rods via in situ hybridization: a potential material as internal fixation of bone fracture," Biomaterials, vol. 25, no. 5, pp. 779-785, 2004.

[36] J. Zhang, X. Lu, G. Feng et al., "Chitosan scaffolds induce human dental pulp stem cells to neural differentiation: potential roles for spinal cord injury therapy," Cell and Tissue Research, vol. 366, no. 1, pp. 129-142, 2016.

[37] D. G. Soares, H. L. Rosseto, D. S. Scheffel et al., "Odontogenic differentiation potential of human dental pulp cells cultured on a calcium-aluminate enriched chitosan-collagen scaffold," Clinical Oral Investigations, vol. 21, no. 9, pp. 2827-2839, 2017.

[38] H. Ghasemi Hamidabadi, Z. Rezvani, M. Nazm Bojnordi et al., "Chitosan-intercalated montmorillonite/poly(vinyl alcohol) nanofibers as a platform to guide neuronlike differentiation of human dental pulp stem cells," ACS Applied Materials \& Interfaces, vol. 9, no. 13, pp. 11392-11404, 2017.

[39] N.-C. Cheng, S. Wang, and T.-H. Young, "The influence of spheroid formation of human adipose-derived stem cells on chitosan films on stemness and differentiation capabilities," Biomaterials, vol. 33, no. 6, pp. 1748-1758, 2012.

[40] A. C. A. Pellicioli, M. D. Martins, C. S. Dillenburg, M. M. Marques, C. H. Squarize, and R. M. Castilho, "Laser phototherapy accelerates oral keratinocyte migration through the modulation of the mammalian target of rapamycin signaling pathway," Journal of Biomedical Optics, vol. 19, no. 2, p. 028002, 2014.

[41] P. R. Garrido, A. C. F. Pedroni, D. P. Cury et al., "Effects of photobiomodulation therapy on the extracellular matrix of human dental pulp cell sheets," J. Photochem. Photobiol. B Biol, vol. 194, pp. 149-157, 2019.

[42] S. Hosseinpour, R. Fekrazad, P. R. Arany, and Q. Ye, "Molecular impacts of photobiomodulation on bone regeneration: a systematic review," Progress in Biophysics and Molecular Biology, vol. 149, pp. 147-159, 2019.

[43] C. Estrela, B. S. Freitas Silva, J. A. Silva, F. P. Yamamoto-Silva, D. . S. Pinto-Júnior, and R. S. Gomez, "Stem cell marker expression in persistent apical periodontitis," Journal of Endodontics, vol. 43, no. 1, pp. 63-68, 2017.

[44] T. W. Lovelace, M. A. Henry, K. M. Hargreaves, and A. Diogenes, "Evaluation of the delivery of mesenchymal stem cells into the root canal space of necrotic immature teeth after clinical regenerative endodontic procedure," Journal of Endodontia, vol. 37, no. 2, pp. 133-138, 2011.

[45] M. Frozoni, M. R. Marques, R. Gilioli, L. F. Silva, A. D. Soares, and A. A. Zaia, "Required time for migration of bone marrowderived cells to dental pulp after bone marrow transplantation," Journal of Endodontia, vol. 44, no. 3, pp. 438-445, 2018.

[46] C. Moura-Netto, L. S. Ferreira, C. M. Maranduba, A. C. V. Mello-Moura, and M. M. Marques, "Low-intensity laser phototherapy enhances the proliferation of dental pulp stem cells under nutritional deficiency," Brazilian Oral Research, vol. 30, no. 1, 2016.

[47] L. S. Ferreira, I. M. A. Diniz, C. M. S. Maranduba et al., "Shortterm evaluation of photobiomodulation therapy on the proliferation and undifferentiated status of dental pulp stem cells," Lasers in Medical Science, vol. 34, no. 4, pp. 659-666, 2019.

[48] L. Almeida-Lopes, J. Rigau, R. Amaro Zângaro, J. GuidugliNeto, and M. M. Marques Jaeger, "Comparison of the low level laser therapy effects on cultured human gingival fibroblasts proliferation using different irradiance and same fluence*," Lasers in Surgery and Medicine, vol. 29, no. 2, pp. 179-184, 2001.

[49] A. N. Pereira, C. de Paula Eduardo, E. Matson, and M. M. Marques, "Effect of low-power laser irradiation on cell growth and procollagen synthesis of cultured fibroblasts," Lasers in Surgery and Medicine, vol. 31, no. 4, pp. 263-267, 2002.

[50] F. Asghari Sana, M. Çapkın Yurtsever, G. Kaynak Bayrak, E. Ö. Tunçay, A. S. Kiremitçi, and M. Gümüşderelioğlu, "Spreading, proliferation and differentiation of human dental pulp stem cells on chitosan scaffolds immobilized with RGD or fibronectin," Cytotechnology, vol. 69, no. 4, pp. 617-630, 2017.

[51] I. M. Zaccara, A. P. Jardine, L. B. Mestieri et al., "Influence of photobiomodulation therapy on root development of rat molars with open apex and pulp necrosis," Brazilian Oral Research, vol. 33, p. e084, 2019. 